\title{
GOVERNMENT PROGRAMS FOR SUPPORTING AND PROTECTING YOUNG CONSUMERS - INSTRUMENTS OF FOOD POLICY IN ROMANIA
}

\author{
Corina Ene ${ }^{1}$
}

\section{Summary}

In recent years, a number of preoccupations at the global, regional and national level have been aimed to find solutions to the current problems in the field of food consumption in children and young people, given the fact that both food insufficiency and food abuse generate negative effects on health.

In Romania, the economic context consisting of the existence of a large number of children whose diet is insufficient made European programs for granting food in schools, during class hours, to be useful and to have social relevance.

The article examines, starting from the Romanian legislative framework underpinning such programs, the coordinates of these efforts, concluding that they represent in the same time instruments of national food policy.

Key words: children's diets, obesity, milk and fruit schemes, food and nutrition policy.

JEL: D18, H 53, J13, Q18

\section{Introduction}

While most specialists and policy makers agree on the fact that diet is extraordinarily important in actual society, in the last years, alarming signals were launched at global level regarding two opposite tendencies: on the one hand, a large part of the world population still suffers from hunger and sub-nutrition and, on the other, in developed countries, food and inappropriate diets became a cause of illness: obesity, anorexia, cardiovascular diseases, diabetes and gastric problems - generating unaffordable expenditures in health systems and associated social costs.

A worrying fact is that, in most countries, children's diets tend to be oriented towards highly processed foods, while the amount of fruit, vegetables and milk included in daily food intake is decreasing below the recommended daily intake.

1 Ph.D., Associate Professor, Petroleum-Gas University of Ploiesti, Faculty of Economic Sciences, B-dul Bucuresti, no. 39, 100.680, Ploiesti, Romania, Phone: +40 726259 030, E-mail: enecorina@yahoo.com

EP 2014 (61) 2 (275-289) 
Studies conducted by the World Health Organisation (WHO) within the European Union show that obesity among European children is rising rapidly in all the Member States: one of three European children was overweight or obese in 2012, compared to one in three in 2008 (http://ec.europa.eu/agriculture/sfs/eu-countries/index en.htm). It seems that this phenomenon is relatively recent (European Heart Network, 2006).

At present, young people in the EU (European Union, 2014):

o consume more fast-food and sugar-sweetened beverages;

$\mathrm{o}$ eat outside the home more frequently and spend less time eating family meals;

$o$ are affected by harmful effects of television viewing and internet use on the eating habits, in terms of greater consumption of sweetened beverages and exposure to advertising of unhealthy products.

Considering that obese children are exposed to higher increased risk of various diseases (including cardiovascular disease, diabetes, liver disease and certain forms of cancer), besides the psychological distress (European Heart Network, 2006), social stigmatisation and mental health problems (European Union, 2014), in March 2004, the European Heart Network (EHN) started a project on "Children, obesity and associated avoidable chronic diseases". The project shown the imperative to act immediately through the collaboration of all parties involved, using a set of well-targeted policies. EHN issued a report which establishes ten policy options as a result of consultations (European Heart Network, 2006):

o Food and health education;

o Controlling sales of foods in public institutions;

o Controls on food and drink advertising;

o Subsidies on healthy foods;

o Change planning and transport policies;

o Improve communal sports facilities;

o Improve training for health professionals;

o Improved health education;

o Common Agricultural Policy reform;

o Mandatory nutritional information labelling.

EHN insisted that this approach should be sustained by different measures proposed by international organisations, national task forces on obesity and national Government policies, with an emphasis on food polices for schools and restriction of TV advertising and marketing of unhealthy foods to children (European Heart Network, 2006).

In 2007, as response to the challenge of overweight and obesity, The European Commission launched the White Paper on a Strategy for Europe on Nutrition, Overweight and Obesityrelated Health issues, establishing the need action in six priority areas: better informed consumers, making the healthy option available, encouraging physical activity, developing 
the evidence base to support policy making, developing monitoring systems and making children and young people and low socio-economic groups a priority (http://www.euro. who.int).

For the implementation of the Strategy, a range of policies have been developed at the EU-level, based on two key-instruments: the High Level Group on Nutrition and Physical Activity and the EU Platform for Action on Diet, Physical Activity and Health.

As a result of the collaboration between WHO and the EU, the "EU Action Plan on Childhood Obesity 2014-2020" was adopted at a high level meeting, mentioning that "childhood obesity rates at a worrying trend" and establishing specific objectives and areas of action (http://www. euro.who.int).

As childhood represents a decisive period for installing good habits and infusing healthy behaviours and knowledge, educational centres are areas in which effective action can be taken to generate long-term changes towards healthy lifestyle.

Many studies points out that dietary habits acquired in childhood can influence behavioural patterns, food preferences and choices which persist throughout adulthood, being a major component of a healthy lifestyle (Ene, 2008; European Parliament, 2013; Jensen et al., 2012; WHO, 2006).

As a consequence, in order to prevent or reverse the adverse health effects of overweight and poor eating habits, nutrition interventions should occur early in childhood and adolescence as critical periods in terms of diets (WHO, 2006).

In the light of the declining trend in the fruit, vegetables and milk consumption, two schemes were set up at European level: the School milk scheme, starting 1977 and the School fruit scheme, starting 2009 (European Commission, 2014). Across the EU, around 30 million children benefit from these programmes each year (http://ec.europa.eu/news/ agriculture/140204 en.htm), (over 20 million for the milk scheme and 8.5 million for the school fruit scheme (European Commission, 2014)).

The School Milk Scheme and the School Fruit Scheme were introduced by the Romanian government in schools starting with 2002 and 2010 respectively, being $75 \%$ financed by EU funds, aiming at the distribution of fruit and milk in schools and encouraging education on healthy eating.

In this context, in Romania there are a number of preoccupations and programs that reflect the interests of public institutions to promote healthy eating and adequate nutrition for children and adolescents - as major components of public health, reflected in the requirements for food and nutrition in schools.

In terms of institutional framework, the implementation and the success of these programs depend on the effective involvement of relevant stakeholders: Ministry of Agriculture and Rural Development; Ministry of Health; Ministry of Education, Research, Youth and Sport. 
In terms of legislation, a series of specific regulations refers to the need to ensure a sufficient and balanced nutritional intake in the institutions for education and recreation for children and youth.

\section{Legal regulations applicable to food in the institutions for education and recreation of children}

As stated in the text of Article 17 of Order no. 1955/1995 for the approval of hygiene norms for institutions for care, education and training of children and adolescents (with subsequent modifications and completions), the management of all recreation and education institutions (nurseries and kindergartens with prolonged and weekly program, boarding schools with canteens, orphanage preschools and schools, higher education institutions with student dining canteens, summer camps) will provide a collective diet adapted to their age, health status, specific activity and season, ensuring daily caloric and nutritive needs as recommended by the Ministry of Health. These needs are set in tables establishing daily requirements of calories and nutrients for children and adolescents, respectively estimated daily requirements of various food groups to be included in dietary composition for children and adolescents (bruto commercial quantities).

The same normative act sets out the requirements that must be met for correct composition of the menu in the institutions for education and recreation of children and youth. According to Article 17 of Order no. 1955/1995, the following requirements should be observed for a correct menu:

o to avoid the association foods from the same group in the dishes served (for example, breakfast will not consist of tea with bread and jam, but with meat or milk derivatives; though, milk can be used along with bread and jam or biscuits; main dishes at lunch will not contain mainly carbohydrates - grains; for instance, soup with dumplings and steak will have a vegetables garnish instead of pasta);

o to avoid, at dinner, foods that require effort to digest, having a strong digestive stimulant effect or, if combined, generate adverse gastrointestinal effects (such as baked beans with yogurt or stewed fruit);

o to allow dishes such as stuffing or roasted schnitzel, only if they have been previously cooked by boiling or as sausage which were fried or prepared in the oven. Eggs are recommended to be served as scrambled eggs in the oven and not baked or fried;

o to enrich the content of vitamins and minerals through the use of raw food salads and leafy vegetables added to soups and borsches;

o to ban on using creams with eggs and sour cream, mayonnaise, regardless of the season, and also boiled eggs (uncut after boiling).

In terms of legal requirements necessary for ensuring healthy diets in schools, the Ministry of Public Health shall establish and update the list of foods not recommended for preschool children and schoolchildren, as suggested by nutrition experts. According to Article 10 of 
Law no. 123/2008 for healthy eating in pre-university education, the preparation, marketing and distribution of any food contained in the list are prohibited within these institutions.

The list of foods not recommended for preschool children and schoolchildren (specifying products, criteria and limits) are provided in Annex 1 which is an integral part of the Ministerial Order No. 1563/2008 - which addresses the approval of the list of foods not recommended for preschool children and schoolchildren and the principles underlying healthy diets for children and adolescents.

The list includes foods such as: foods high in sugars (15 g sugars/100 g, e.g.: cakes, candy); high-fat foods (e.g. hamburgers, pizza, pastry type products, French fries); foods with high salt content (over 1.5 g salt/100 g, e.g.: chips, crackers, salted sticks, snacks); soft drinks (except for bottled drinking water or bottled mineral water); foods high in calories per unit of sale (over $300 \mathrm{kcal}$ per unit of sale); unpackaged foods (e.g. bulk foods); unlabelled food (which do not comply with Government Decision No. 106/2002 on food labelling, with subsequent amendments).

This regulation (Order No. 1563/2008) also establishes the criteria for which specific foodstuffs or food items which should not be recommended. As a consequence, food items listed in the Order are banned from sale within schools in order to encourage schoolchildren to adopt healthy dietary habits (WHO, 2013).

In addition to the list of not recommended foods, banned from sale inside pre-university education institutions, the above mentioned Order provides:

o underlying principles of a healthy diet for children and adolescents;

o daily requirements of calories, nutrients and minerals for children and adolescents;

o food equivalents, the estimated daily requirement of various food groups necessary for meals planning for children and adolescents, indicative data on the caloric value of food and nutritional characteristics of the food groups used for compiling menus for children and adolescents (bruto commercial quantities);

o the food pyramid for nutrition of children and adolescents, according to caloric needs, food groups and age group.

Another measure aimed at protecting children and adolescents as consumers refers to prohibiting the sale of alcoholic beverages inside educational institutions. Thus, according to Article 1(1) of the Government Decision (G.D.) No. 128/1994 on measures for ensuring the physical and moral development of pupils and students, the sale or exposure for sale of alcoholic beverages is prohibited within educational units of all grades, boarding schools, places of accommodation for pupils and students, in the courts of such buildings, and also in the sidewalks or access paths to these units.

This requirement must be complied with, as provided for in Article 2 of the same act, also by the businesses servicing the in-house buffets/cafeterias or supplying pupils and students with bakery products and beverages, based on the operational specific acceptance of the school management. 
Besides the mentioned requirements, Romania is among the Member States participating in the two European school schemes, the School Milk Scheme (known as the "Croissant and Milk" Programme - in Romanian: "Cornul si laptele") and the School Fruit Scheme (known as the "Apples in Schools" Programme - in Romanian: "Mere in scoli”), which are partially financed by the EU.

\section{General coordinates of the "Croissant and Milk" Programme in Romania}

According to Emergency Government Ordinance (E.G.O.) No. 96/2002 on providing dairy and bakery products for pupils in grades I-VIII of public and private education and for preschool children in private kindergartens with normal program of 4 hours (with subsequent modifications and completions), pupils in primary and secondary public and private schools, as well as preschool children in public and private kindergartens with normal program of 4 hours are given daily, for free, on condition they are present at the program, dairy and bakery products according to a daily limit value of 1.17 lei/ pupil or preschool child.

The limit value shall be updated by Government Decision, depending on the evolution of prices and tariffs, currently being established by G.D. No. 714/2008 on updating daily limit value on dairy and bakery products for pupils in grades I-VIII of public and private education and for preschool children in private kindergartens with normal program of 4 hours and for approval of content/technical specifications of procedures for the award of contracts for the supply of dairy and bakery products for school and preschool (with subsequent modifications and completions).

The text of Article 1 of E.G.O. No. 96/2002 requires that, in order to maintain the health of children included in the scheme, under this program will be distributed only milk and milk derivatives prepared in accordance with the requirements of Regulation (EC) no. $852 / 2004$ on the hygiene of foodstuffs, with subsequent amendments, which will bear the identification mark provided for in Regulation (EC) no. 853/2004 laying down specific hygiene rules for food of animal origin, with subsequent amendments.

Regarding the types of products allowed to be distributed under "Croissant and Milk" Programme, Annex 1 to G.D. No. 714/2008 provides technical specification for the procedures for the assigning of contracts for the supply of dairy and bakery products for school and preschool.

Thus, regulation establishes that following products can be distributed within the scheme:

a) heat-treated milk, UHT and pasteurized milk and fermented milk products containing heat-treated milk at least $90 \%$ by weight: yogurt, buttermilk or kefir, which meet the specified requirements, packed in $200 \mathrm{ml}$ units for milk and in packs whose weights is expressed in grams for fermented milk products;

b) bakery products: croissants or bars and derivatives: plain bagels or dry biscuits, in packs of $80 \mathrm{~g}$ /unit. 
Products distributed within the "Croissant and Milk" Programme must meet several requirements for quality and hygiene, resulting in provisions, criteria and limits set out in the list in Annex no. 1 which is an integral part of the Ministerial Order No. 1563/2008.

Distributed products shall also comply with the technical specifications on quality, safety and perishability (deadline for consumption), the conditions for transport and distribution, packaging, labelling and marking. These requirements stipulate, inter alia, the following:

o the necessity to observe microbiological criteria for foodstuffs;

o a minimum protein content of $3.2 \%$ and a minimum of $1.8 \%$ fat in milk consumption in order to maintain the normal levels of health and nutrition of children;

o providing medical prescribed diets for special groups of consumers - children with diabetes, gluten and lactose intolerance;

o ensuring proper product storage until serving, using dedicated facilities with hygienic conditions, according to the specifications given by the manufacturer;

o food will be transported from the supplier to schools only by special vehicles, authorized under applicable law;

o food distribution will be made only by persons who have acquired basic knowledge of hygiene and passed medical examination performed according to applicable law;

o inscription of warnings indicating that the product is distributed for free, its sale being prohibited.

Regarding the responsibility for supervising the hygienic conditions related to the distribution of products included in the "Croissant and Milk" Programme, as required by Article 5 of the E.G.O. No. 96/2002, county councils and sector mayors have the obligation to monitor and verify the due process of supply and sanitary conditions on distribution to pupils of dairy and bakery products.

\section{General coordinates of the Programme promoting the consumption of fresh fruit in schools}

The Programme promoting the consumption of fresh fruit in schools, implemented in our country under the provisions of E.G.O. No. 24/2010 on the implementation of the program promoting the consumption of fresh fruit in schools (with subsequent modifications and completions), aims to simultaneously encourage the consumption of fruit in schools and establish healthy eating habits among school-age children, stimulating domestic production the fruit in the same time.

According to Article 6(1) of E.G.O. No. 24/2010, as in the "Croissant and Milk" Programme, only pupils present in class are entitled to the right to receive fresh fruit (an apple a day).

The main requirements on quality and hygiene of fruit distributed within the programme promoting the consumption of fresh fruit in schools can be found in Annex 1 (Technical specifications for the procedures for the assignment of contracts for the supply of fresh 
fruit in schools) which is an integral part of the Order of Minister of Agriculture and Rural Development No. 243/2012 on providing fresh fruit in schools.

According to these requirements, the program will provide apples with a minimum weight of 100 grams, falling within the "Extra" and/or Ist Class, according to the Standard for apples sale provided in Annex I "Marketing standards referred to in Article 3 " - part B "Specific Marketing Standards “ - part 1" Marketing Standard for apples" to Regulation (EU) no. 543/2011 of 7 June 2011 laying down detailed rules for the application of Council Regulation (EC) No 1234/2007 in respect of the fruit and vegetables and processed fruit and vegetables sectors.

Further specifications require that:

o apples must be whole, healthy, washed, clean and free of any visible foreign matter, free from pest and disease attacks, without excess external moisture, without foreign smell or taste, to withstand transport and handling;

o apples batches will be accompanied by test reports on the content of pesticide and heavy metals residues, delivery notes, certificates of conformity;

o transport and distribution vehicles will ensure the integrity of apples until the delivery to the recipient;

o for storage, schools will provide and will use dedicated facilities for preserving apples in hygienic conditions.

The responsibility for ensuring the provision, reception and distribution of fresh fruit and confirmation documents underlying payment rests directly, according to Article 6(2) of E.G.O. No. 24/2010, with the main loan authorizing body (presidents of county councils, respectively mayors of Bucharest districts) and school directors.

Also, according to Article 6(3), presidents of county councils and mayors of Bucharest districts are required to track and verify the proper conduct of the supply process and the principals of educational units are responsible for compliance with hygiene conditions on the distribution of fresh fruit to pupils.

For the current school year (2013-2014) the programme promoting the consumption of fresh fruit in schools in Romania consists of the free daily apple distribution to pupils in grades I-VIII and preparatory class form public and private schools and in implementing accompanying measures in the period 16 September 2013 - 20 June 2014.

According to provisions of the G.D. No. 800/2013, for the school year 2013 - 2014 granted apples will fit within the daily value of 0.37 lei/pupil for a period of 85 days of schooling, complying with the amount of each budget year. Besides fruit distribution, G.D. No. 800/2013 also establishes accompanying measures in the school year 2013 2014, according to Article 2, as follows:

a) organizing visits to fruit and vegetable farm, to fruit or vegetable research stations, to "Harvest Days", exhibitions, fairs and other events and/or activities; 
b) organizing thematic contests with prizes - as educational practical ways to help pupils develop skills by gardening activities.

Prizes awarded on the occasion of the competitions include:

o individual awards: books, diplomas, atlases, DIY kits, baskets of fruit and vegetables, fruit trees seedlings, vegetables or flowers seedlings;

o awards for the educational unit: classrooms and laboratory equipment, teaching materials.

\section{Penalties applicable in case of infringements of the provisions on food by the institutions for education and recreation of children}

Violation of these provisions entails a series of sanctions, in accordance with Article 55 of Chapter XIII (Contravention to the rules on the organization and functioning of institutions for the protection, education, training, recreation and leisure for children and youth) of G.D. No. $857 / 2011$ establishing and sanctioning offenses to public health standards. In this context, the following acts having impact in the field of food and nutrition are considered contraventions and are punishable by a penalty of 1,000 to 2,000 lei for individuals, respectively a penalty of 5,000 lei to 10,000 lei for legal persons:

o infringement of the principles underpinning a healthy diet for children and young people, considering the rules in force;

o lack of endorsement and approval of the menu developed for children and young people in both public and private education units, including camps, holiday centres, units and establishments providing similar services for hosting pupils after school hours, by a medical professional and the director of the unit;

o preparation, sale and distribution of food products that do not comply with the limits for which they become not recommended to preschool and school children, according to the list established by the Ministry of Health;

o failure to comply with the conditions regarding the composition, quality, labelling and packaging of dairy and bakery products distributed to pupils and pre-schoolers the rules in force;

o failure to comply with the conditions regarding the transport, distribution and storage of dairy and bakery products distributed to pupils and preschool children under the rules in force.

\section{Other measures}

According to a project for a Government Ordinance initiated by the Ministry of Education, it was proposed that starting school year 2008-2009, public and private kindergarten and primary schools (pupils in grades I-IV) distribute weekly to each pupil 60 grams of honey, as a dessert to the "Croissant and milk" menu, but the proposal was implemented only temporarily, within a small number of educational units. 
Distributing honey as a nutritive supplement in schools would primarily aim at lowering dropout among children from poor families, but also would bring nutritional benefits.

At the same time, the programme would generate positive economic consequences for beekeepers, stimulating them to deliver quality products on domestic market and not only for export; moreover, domestic consumption would increase, thus inducing benefits on children's health.

\section{A Future trend for European School Schemes}

A press release form the European Commission on 30 January 2014 informs the public that the Commission launched a proposal to combine and reinforce existing school milk and school fruit schemes under a joint framework, in a context of declining consumption among children for these products. The proposal builds on the findings of evaluation reports and the public consultation carried out in 2013.

The new scheme will have a budget of $€ 230$ million per school year ( $€ 150$ million for fruit and vegetables and $€ 80$ million for milk) (European Commission, 2014). Participation in the new scheme will continue to be voluntary, and EU countries will have the flexibility to choose which foods to distribute.

As a result, combining the two schemes is intended (European Commission, 2014; http:// ec.europa.eu/agriculture/sfs/eu-countries/index en.htm):

o to address poor nutrition more effectively;

$\mathrm{o}$ to reinforce the educational elements of the programmes;

$\mathrm{o}$ to contribute in the fight against obesity;

$\mathrm{o}$ to put greater focus on educational measures to improve children's awareness of healthy eating habits, the range of farm produce available, as well as sustainability, environmental and food waste issues (European Commission, 2014);

$\mathrm{o}$ to reduce the administrative and organisational burdens of implementing them for schools and national authorities;

o to make distribution more cost-effective.

\section{Preoccupations and contributions of The National Authority for Consumers Protection to support young consumers in terms of food consumption}

Surveillance and controls - Through its representatives, The National Authority for Consumers Protection (NACP) monitors economic operators involved in the manufacture and distribution of food for children and adolescents within special schemes, ensuring that providing food implies utmost responsibility and does not put children's health at risk in any way. Periodically, NACP commissioners check the application of legal provisions regarding dairy and bakery products for both preschool children in kindergartens and pupils in primary and secondary public education, assessing the implementation of the program promoting the consumption of fresh fruit in schools. 
Thus, in the period 16 September 2013 - 31 January 2014, 1579 control actions were performed, of which 1,014 in schools and 542 in kindergartens, on 11 manufacturers and 12 distributors (http://www.anpc.gov.ro/).

As a consequence of identified deficiencies, $5259 \mathrm{~kg}$ of milk, bakery products and apples in amount of 14,483 lei - were withdrawn form distribution due to the fact they were unfit for human consumption, and 10 sanctions were applied, consisting of six penalties totalling 59,000 lei and 4 warnings.

Several infringements of legal provisions were identified during the controls, including (www.anpc.gov.ro/):

1. Exceeding the expiration date established by normative acts of imprinted on package (e.g., exceeding the limited date of consumption for croissants - 48 hours from the time of manufacture, as regulation provide);

2. Distribution of qualitatively and/or quantitatively non-conforming products (e.g. changes in taste and colour, negative deviations of the net amount);

3. Failure to the comply with the delivery schedule (biweekly and even weekly distribution instead of daily supply);

4. Failure to comply with conditions of transport, warehousing and storage (e.g. lack of dedicated facilities for receiving and storage of food until distributing it to pupils);

5. Non-compliance with the rules for labelling, marking and packaging (e.g. lack of required information on the label; incomplete, illegible use-by date).

\section{The launch of the Code of Ethics regarding Food Marketing to Children}

In the context of Romanian legislation created by Law No. 363/2007 on combating unfair commercial practices, unfair trade practices also refer to including in an advertisement a direct exhortation to children to buy advertised products or persuade their parents or other adults to buy for them the promoted products.

Taking into account the need to provide consistent legislation, a member of Parliament and NAPC, along with other stakeholders, launched the initiative to develop and publicly debate an ethical code regarding food marketing to children, which was later finalized and approved.

This code represents a significant step towards compliance with the general ethical rules of marketing and, in particular, with consumers' rights. The Code contains (Code of Ethics, 2008):

o general ethical principles of marketing of food and non-alcoholic beverages;

o ethical principles for marketing of food and non-alcoholic beverages to children.

The Code defines the Minimum Nutritional Criterion establishing requirements and limitations which foodstuffs intended for children should meet (Code of Ethics, 2008), in 
order to not affect health and not predispose them to obesity, being the main landmark in establishing beneficial food for the harmonious development of the child.

Voluntary adoption of this set of rules means that economic operators cease to advertise - by any means of marketing - products not meeting the Criterion and respect the right of children not to be influenced or not to influence parents to buy certain products. Moreover, research suggests that banning ads targeted at children is a very effective policy tool for reducing fast-food consumption (Jensen et al., 2012).

\section{Conclusions and trends}

Young consumers' health, security and safety are among primary concerns, both at global, European and national level. Government responsible, specialists, policy makers agree more and more today that steps must be taken to provide better food and nutritional options for pupils in schools. In this context, three directions of concern and action are mostly relevant and should be reflected in food and nutrition policy at national level:

o the "food security" dimension; for many children, the foodstuffs granted through government programs in educational institutions represent an important meal. Children from disadvantaged families with low incomes are unable to acquire basic food intake every day, so that programmes distributing milk and bakery products, fruit and/or honey play a vital role in food security.

o the "food safety" dimension; government aid granted by these programs must fulfil both the nutritional role and the innocuity function, so that it should not induce any threat to consumers' health. Therefore, manufacturing, transportation, distribution, storage and allocation of such foods require constant monitoring of these programs and drastic sanction in case of breaches found.

o the "food and nutrition" dimension; actually, these programs represent food and nutrition policy instruments at national level. Where possible, it appears necessary to reassess of the distribution of these foods taking into account:

$\S$ the proper way of combining foodstuffs;

$\S$ the right time for consumption during the school program.

Moreover, further possibilities should be investigated in order to avoid the repetitive nature of the consumption of the same food every day, as it creates monotony and can lead to situations where targeted consumers waste, throw away the products or find other uses for them (e.g. play) thus compromising their purpose.

Currently, it is imperative that food and nutrition policies aimed at young consumers to focus on both sides of the problem: insufficient food intake, respectively excessive and unhealthy food intake, especially since research show there is a strong correlation between lower socioeconomic status, physical inactivity, food and nutrition insecurity and obesity.

In support of the children from low-income families, the "Croissant and milk" scheme could be replaced by a hot meal with two dishes, particularly in schools that own a canteen or 
can cooperate with catering units. Nevertheless, milk distribution is sustained partially by European funding, so it is not possible to redirect these funds to canteens. In this context, the increasing involvement of mayors and local councils in funding school canteens is required, where it is a social necessity.

In order to avoid excessive or unhealthy food intake, adopting the voluntary set of rules contained in the code of ethics regarding food marketing to children by more and more operators involved in the promotion of products for children is of paramount importance. In this way, strong actions can be taken on the compliance with general ethical norms of food marketing to children, proving that food industry is equally interested in the health of citizens as consumers themselves.

Such approaches cannot be successful sustainable without proper education regarding diet and nutrition. This kind of education require the introduction of appropriate subjects of study (study of food, nutritional health and dietary habits) in school curricula and/or by programmes offered by local authorities or private bodies as a means of improving the health and wellbeing of children, ensuring better learning ability and academic performance.

Schools represent a relevant opportunity for prevention in this field, because they reach large numbers of people, including youth, school staff, families and community members.

It is critical that food and nutritional education starts early in consumers' life and different types of measures should be address directly to children and adolescents, involving the intervention and sustaining from all parties involved: local and national authorities, parents, school representatives, pupils themselves. There is a clear need for the public and private authorities working together to help youth attain their full educational potential and good health by providing them with both the skills and social support necessary for adopting longterm healthy eating habits - and this is indeed a matter of urgency.

\section{Literature}

1. Code of Ethics regarding Food Marketing to Children (2008), (Codul etic pentru marketingul produselor alimentare destinate copiilor), retrieved at www.urbaniulian. ro/2008/09/25/codul-etic-pentru-marketingul-produselor-alimentare-destinate-copiilor/ (accessed 14 April 2014).

2. Ene, C. (2008): Food and Nutrition Policies for Young Consumers, in "Theoretical Developments in Contemporary Economics" - Proceedings of "Research and Education in an Innovation Era" International Conference, Aurel Vlaicu University, 20-21 Nov, Mirton Publishing House, Timişoara, pp. 192-200.

3. European Commission (2014): Eat well - feel good: Commission proposes to combine and reinforce existing school milk and school fruit schemes, press release on 30/01/2014, IP/14/94.

4. European Heart Network (2006): Policy options to prevent child obesity, October 2006.

5. European Parliament (2013): Draft Report on European gastronomic heritage: cultural and educational aspects, (2013/2181(INI)), Committee on Culture and Education, 
26.11.2013.

6. European Union (2014): EU Action Plan on Childhood Obesity 2014-2020, 24 February 2014 (updated 12 March 2014).

7. Jensen, T. S., Glyki, E., Hayles, A., Normander, B. (2012): From Consumer Kids to Sustainable Childhood, World watch Institute Europe, Copenhagen, Denmark.

8. Order of Minister of Agriculture and Rural Development No. 243 of 5 November 2012 on providing fresh fruit in schools, Official Gazette of Romania, no.756/9, Nov 2012.

9. Order of Minister Health No. 1955 of 18 October 1995 for the approval of hygiene norms for institutions for care, education and training of children and adolescents, Official Gazette of Romania, no. 59 bis/22 Mar 1996 (with subsequent modifications and completions).

10. Order of Minister of Public Health No. 1563 of 12 Sept 2008: approval of the list of foods not recommended for preschool and schoolchildren and the principles underlying health diets for children and adolescents, Official Gazette of Romania, no. 651/15 September 2008, available at: www.dreptonline.ro/legislatie/ordin_lista_alimente nerecomandate prescolari_scolari 1563 2008.php (accessed 5 April 2014).

11. Romanian Government. G.D. No. 128/1994 on measures for ensuring the physical and moral development of pupils and students, Official Gazette of Romania, no. 92/8 April 1994.

12. Romanian Government. E.G.O. No. 96/2002 on providing dairy and bakery products for pupils in grades I-VIII of public and private education and for preschool children in private kindergartens with normal program of 4 hours, Official Gazette of Romania, No. 631/26 Aug 2002 (with subsequent modifications and completions).

13. Romanian Government. G.D. No. 714/2008 on updating daily limit value on dairy and bakery products for pupils in grades I-VIII of public and private education and for preschool children in private kindergartens with normal program of 4 hours and for şi pentru approval of content/technical specifications of procedures for the award of contracts for the supply of dairy and bakery products for school and preschool, Official Gazette of Romania, No. 511/8 July 2008 (with subsequent modifications and completions).

14. Romanian Government. E.G.O. No. $24 / 2010$ on the implementation of the program promoting the consumption of fresh fruit in schools, Official Gazette of Romania, No. 204/31 Mar 2010 (with subsequent modifications and completions).

15. Romanian Government, G.D. No. 800/2013 establishing fruit distributed, period and frequency of distribution, the daily limit value / pupil and the funds necessary for the distribution of fruit and fruit distribution accompanying measures, the necessary budget, and the way of implementation and management at the level of public administration, in the program promoting the consumption of fresh fruit in schools in the school year 20132014, Official Gazette of Romania, no. 652/23, Oct 2013.

16. Romanian Government, G.D. no. 857/2011 on establishing and sanctioning contraventions to public health rules, Official Gazette of Romania, no. 621/1, Sept 2011.

17. Romanian Parliament, Law No. $123 / 2008$ for healthy eating in pre-university education: food law banning fast food in schools, Official Gazette of Romania, No. 410/02 June 
2008, www.dreptonline.ro/legislatie/lege_alimentatie_sanatoasa_unitatile_invatamant preuniversitar_123 2008.php (accessed 5 April 2014).

18. Stancu, A. (2012): Correlation between Food Quality and Preservation Methods, in The USV Annals of Economic and Public Administration, vol. 12, Issue 2(26), pp. 43-49.

19. WHO (2013): Nutrition, Physical Activity and Obesity - Romania (Country profile).

20. WHO (2006): Food and nutrition policy for schools, Programme for Nutrition and Food Security, WHO Regional Office for Europe, Copenhagen.

21.www.anpc.gov.ro/, accessed 14 April 2014.

22.http://ec.europa.eu/news/agriculture/140204 en.htm (accessed 14 April 2014).

23. http://ec.europa.eu/agriculture/sfs/eu-countries/index_en.htm (accessed 14 April 2014).

24. www.euro.who.int (accessed 14 April 2014). 